\title{
A conversational framework for learning design (in adverse times)
}

Johanna Tomczak

University of Leeds

\section{Eric Bel}

Teesside University

Keywords: learning design; conversation; collaboration; Covid-19.

\section{The challenge}

In this article, we present a summary of a series of exchanges which took place in 20202021 between us - a novice postgraduate researcher ( $\mathrm{PgR}$ ) involved in some undergraduate teaching and an experienced higher education teacher and facilitator of learning (FoL). Despite the difference in our knowledge of academia, we both faced the same questions when forced to facilitate learning at a distance, which is the starting point of this short piece. This is followed by a reflective account of some of the outcomes of the conversation between us. One of our conclusions was that communicating with each other, even at a distance, enabled us to seek reassurance and develop solutions to our respective questions. Another key realisation was that the first stage in responding to adverse situations in a learning and teaching context should not be technological, even at a distance, but a 'conversational mindset', which provides a framework for communication and collaboration.

This is what the PgR said about the problem that she encountered as a postgraduate student, and also as a tutor, supporting learners at a distance:

The challenge for me was finding my way through postgraduate learning, engaging with my supervisors and fellow researchers, and also with learners in seminars that I was asked to facilitate. The sudden absence of direct contact with other members 
of the university community was problematic. I had come to England to build personal and professional networks, and I found myself away from my home country and feeling completely isolated. I was overwhelmed with negative thoughts, and my self-confidence diminished rapidly. I could not figure out how I would support learners at a distance, how I would check their progress and how I would know myself that I was learning, how I could enthuse others when I was struggling with my own motivation.

This reflective comment made by the PgR enabled the FoL to verbalise what had been, until now, just an intuition: that isolation and the resulting feeling of solitude were real challenges for learners and tutors alike, when studying or working at a distance. In an attempt to address this issue, for the benefit of the $\mathrm{PgR}$, his own practice and that of tutors he trained, the FoL went on to ask the following question: 'what essential features does distance learning and teaching need to incorporate?'. Indeed, the difficulty the PgR and the FoL both faced, irrespective of their academic experience, was one of disconnection from peers, supervisors and students, as recently reported by many other PgRs in the UK, too (Goldstone and Zhang, 2021; Pitkin, 2020). Redefining one's objectives and sense of purpose was also problematic, as documented in a reflective account recently published by one of us (Tomczak, 2021).

\section{The response}

In our conversion, we reacted to the challenge described above differently, but at a conceptual level, our responses were similar.

PgR: In my own teaching, I turned spontaneously to whatever technology I was familiar with and which I thought would enable me to replicate the classroom-based behaviours that I had tested when I was still allowed to work on campus. For example, in order to keep conversations going, I used e-mail extensively, and encouraged learners to do so too, to keep in touch with me. As I was experiencing a disconnection from fellow PgRs and my supervisors, I decided not to allow the same to happen to my students. I kept the conversation going, prompted them to 
communicate with, and learn from, each other as if they were together in a physical classroom.

FoL: I took a similar path. I favoured interactions, be they asynchronous or synchronous. For example, I set learners tasks based on questions, which they were expected to use as prompts in their own time to prepare for synchronous live sessions, during which their proposed answers were discussed. Synchronicity is at the heart of my way of thinking about learning and teaching, but I find asynchronous communication can be equally effective, as long as the learners are able to express their thoughts, make them visible to, and have them tested by, others. To me, what matters is to create the conditions for both communication and collaboration to be maintained, whether on- or off-line, synchronously or asynchronously.

Thus, in our conversation, we agreed that teaching is about providing a suitably scaffolded environment, as well as adaptive guidance (Wood et al., 1978; Salmon, 2011), so that meaningful exchanges between learners, and between learners and tutors, can take place. There is a wealth of literature on the importance of learners' reflective, active and deep engagement with the content of learning sessions and in their approaches to learning (for example, see Ramsden, 2003; Bel and Mallet, 2006; Race, 2015). In fact, Beetham and Sharpe (2013) suggest that tutors should be clear about the expected nature of this process. They identify three main ways of thinking about 'how people learn, and the implications for design' of learning opportunities: 'associative', 'constructive' and 'situative' (Beetham and Sharpe, 2013, p.221).

Through our conversation, it appeared that we had both responded to the challenge described above in a manner that combined those three theories into one way of approaching learning design. We structured our teaching into the delivery of small, connected chunks of learning, enabling the learners to move seamlessly from one to the next stage, after having received regular feedback on their progress. More importantly, this learning journey was not designed to be individual, but a social constructive, dialogical experience. Thus, as recommended by Biggs (1996) and Papert (1996), we designed learning tasks that were as collaborative and authentic as feasible, despite the adverse context we were working in. Although at a distance, learners were asked to undertake some individual tasks in their own time, at their own pace, followed by small-group 
activities, again, managed by the learners themselves, eventually leading to a synchronous, live, whole-class learning and teaching session, facilitated by the tutor. This process allowed learners to develop a sense of belonging to what Wenger et al. (2002) call a 'community of practice'.

\section{Recommendations}

The conversational framework for learning design (in adverse times) described above can be applied to planning and delivering education in the midst of a pandemic or in 'normal' times, in a physical setting or at a distance. In this latter case, the use of digital tools may well be of some help, but for both of us, the greatest influencing factor was conceptualising the tutor's main role as designing connections and sustaining collaboration through conversations. Laurillard (2002, pp.77-78) describes this as a learning and teaching experience that is 'discursive', 'adaptive', 'interactive' and 'reflective', which, for the purpose of this short article, we interpret as:

- discursive - ideas discussed between learners and tutors in a safe environment.

- adaptive - tutor-mediated linking of different perspectives and concepts.

- interactive - stimulating context for learners' actions and peers' and tutor's feedback.

- reflective - tutor-supported learners' evaluation of their own achievement of agreed learning outcomes.

Thus, as shown by our conversation and through this article, we were able to meet in a 'happier medium' to rediscover the joy of connectedness and construct a common understanding and shared response to the challenges we faced. By implementing the above recommendations, conversations between learners, and between learners and tutors, can be maintained and can provide all members with a sense of belonging and nurturing that can only be beneficial to learning and teaching. 


\section{References}

Beetham, H. and Sharpe, R. J. (eds.) (2013) Rethinking pedagogy for a digital age: designing for $21^{\text {st }}$ century learning. $2^{\text {nd }}$ edn. New York: Routledge. Available at: https://doi.org/10.4324/9780203078952 (Accessed: 21 October 2021).

Bel, É. and Mallet, M. (2006) 'Developing reflection in computing education - a teacher's constructionist perspective', Proceedings of World Conference on Educational Media and Technology. Orlando (USA) 30 June, pp.1763-1769.

Biggs, J. (1996) 'Enhancing teaching through constructive alignment', Higher Education 32, pp.347-364. Available at: https://doi.org/10.1007/BF00138871 (Accessed: 21 October 2021).

Goldstone, R. and Zhang, J. (2021) 'Postgraduate research students' experiences of the Covid-19 pandemic and student-led policy solutions', Educational Review, pp.1-22. Available at https://doi.org/10.1080/00131911.2021.1974348 (Accessed: 21 October 2021).

Laurillard, D. (2002) Rethinking university teaching - a conversational framework for the effective use of learning technologies. $2^{\text {nd }}$ edn. London: Routledge. Available at: https://doi.org/10.4324/9781315012940 (Accessed: 21 October 2021).

Papert, S. (1996) 'A word for learning', in Kafai, Y.B. and Resnick, M. (eds.) Constructionism in practice: designing, thinking, and learning in a digital world. London: Routledge. pp.9-24. Available at: https://doi.org/10.4324/9780203053492 (Accessed: 21 October 2021).

Pitkin, M. (2020) Advance HE Postgraduate Research Experience Survey 2020 Global report. York: Advance HE. Available at: https://www.advance-he.ac.uk/knowledgehub/postgraduate-research-experience-survey-2020 (Accessed: 21 October 2021). 
Race, P. (2015) Making learning happen - a guide for post-compulsory education. $3^{\text {rd }}$ edn. London: SAGE Publications Ltd.

Ramsden, P. (2003) Learning to teach in higher education. $2^{\text {nd }}$ edn. London: Routledge. Available at: https://doi.org/10.4324/9780203507711 (Accessed: 21 October 2021).

Salmon, G. (2011) E-moderating: the key to online teaching and learning. $3^{\text {rd }}$ edn. New York: Routledge. Available at: https://doi.org/10.4324/9780203816684 (Accessed: 21 October 2021).

Tomczak, J. (2021) 'Transforming and being transformed - an eclectic learning journey', Sentio 3, pp.90-92. Available at: https://sentiojournal.uk/wpcontent/uploads/2021/10/211004-Sentio-Journal-Issue-3-Tomczak.pdf (Accessed: 21 October 2021).

Wenger, É., McDermott, R. and Snyder W. (2002) Cultivating communities of practice: a guide to managing knowledge. Cambridge, Massachusetts: Harvard Business School Press.

Wood, D., Bruner, J.S. and Ross, G. (1976) 'The role of tutoring in problem solving', Journal of Child Psychology and Psychiatry, 17, pp.89-100. Available at: https://doi.org/10.1111/j.1469-7610.1976.tb00381.x (Accessed: 21 October 2021).

\section{Author details}

Johanna Tomczak is a Postgraduate Researcher at the University of Leeds, where she studies interhemispheric transfer in bilinguals in the School of Psychology. She is an Associate Fellow of Advance HE (AFHEA) and has been involved as a seminar leader in undergraduate teaching since the beginning of her $\mathrm{PhD}$. 
Éric Bel is a Principal Lecturer in Education at Teesside University and an Associate Professor in Learning and Teaching. He gained his PhD from Teesside University, during which he researched language teachers' use of digital technologies. 